\title{
Glazed balconies impact on energy consumption of multi-story buildings
}

\author{
Tiberiu CATALINA ${ }^{1, *}$, Daniel BORTIS ${ }^{1}$, Andreea VARTIRES ${ }^{1}$, Cătălin LUNGU ${ }^{1}$ \\ ${ }^{1}$ Technical University of Civil Engineering, Faculty of Building Services, Bucharest, ROMANIA
}

\begin{abstract}
Through this research we have studied the influence of the closure of the balconies on the temperature and humidity. Three residential apartments with enclosed balconies are monitored simultaneously over two periods: a colder one in March and a warmer one in May providing an overview of the thermal performance of a balcony relative to the interior. The results of the balcony\#1 simulations made with the Trnsys 17 software show a good energy saving in the cold period, but higher cooling consumption in warm weather.The total energy demand difference between closed and open balconies is about $840 \mathrm{kWh}$. The simulation also showed us the close connection between the temperature in the balcony and the solar radiation that both grow and decrease simultaneously. At the end of the two campaigns, we came to the conclusion that a closed and thermally rehabilitated balcony is the best solution, being proven to have a winter advantage, the difference between the outdoor temperature and the balcony temperature being around $15{ }^{\circ} \mathrm{C}$, but a summer disadvantage when temperatures in the balcony greatly increase and may exceed $50{ }^{\circ} \mathrm{C}$, with the risk of overheating the balcony.
\end{abstract}

\section{Introduction}

We conducted this study because most of the Bucharest housing blocks, built on projects developed between 1950 and 1990, show a low thermal insulation, and this translates into high bills for heating. During the winter, much of the heat of an apartment is lost due to the low thermal insulation, although the tenants pay it. For example, a 2-room apartment in a block in Bucharest consumes twice as much thermal energy as an apartment in other European countries.

Increasing energy efficiency can be achieved in several ways, from educating building users to the energy economy, interventions that are available to many, and carrying out an expertise and energy audit, where experts recommend a range of technical solutions modernization. These solutions depend on the type, age and destination of the buildings and constitute what is called the rehabilitation or modernization of the building. The thermal rehabilitation / modernization of a building is to improve it in order to keep the heat inside. This involves adding thermal insulation, sealing, improving or even replacing windows and doors, as well as improving the equipment and facilities with which the building is fitted.[1]

The renovation of the facades of the blocks, together with other measures to modernize the dwelling, is intended to improve the comfort and beautify the living space while also increasing the energy efficiency of the buildings Energy consumption of a building depends on external factors and internal factors. External factors are the climatic parameters of the site: air temperature, wind speed, sunshine, air humidity.

Windows and exterior doors play a particularly important role in ensuring superior thermal performance of buildings, as they can constitute areas of large heat exchange between the interior and exterior of the building during winter and summer.The wall window ratio is important and contributes up to $40 \%$ of the total heat loss caused by the thermal bridges in the building envelope.[2]

It is good to replace the windows with new ones to reduce the energy loss through them.[3]

Building without windows is not a solution because the cost of energy saving is the loss of the benefits of natural light.[4]

Most residential buildings in Romania built before 1990 are fitted with wooden windows with two rows of sashes (double windows). Since they are far from achieving energy performance as required by the current requirements, and in accordance with the thermal insulation level of the opaque areas of the exterior walls, it is necessary to replace them with modern design windows with energetic performance carpentry and insulating glazing.

By replacing traditional double-glazed windows with insulated glass windows and controlled ventilation systems, the following advantages are achieved:

- Decrease of heat exchanges through the glazed surface (which leads to better thermal protection of the indoor

* Corresponding author: author@e-mail.org 
environment both during winter and partly during summer)

- Increase the quality of indoor comfort by ensuring controlled ventilation of the rooms;

- Reduction of outside noise transmission inside the building;

- Conservation of environmental quality by reducing $\mathrm{CO}_{2}$ emissions into the atmosphere;

- Reduced heating / cooling costs;

- In the case of watertight windows, it is necessary to provide in buildings a controlled air freshener system inside the building;

- Installation of windows and exterior doors must comply with the rules of each window system designer.

The optimal design of the building to minimize its lifetime costs requires an annual energy consumption assessment that represents the instantaneous consumption of instantaneous consumption during the heating or cooling period. Instantaneous consumption is the instantaneous charge divided by the efficiency of the heating or cooling equipment.

The calculation methods are of two major types: static (based on degrees-days or temperature intervals) and dynamic methods (based on transfer functions).

\section{Glazed balconies}

K. Hilliaho [5] studied the temperatures on 22 balconies (17 glazed) and adjacent apartments that were monitored to determine the key factors that affect the balcony's ability to heat up and stay warm with the heater. Glazed balconies have been considered in different locations, the number of windows and thermal insulation of buildings, the tightness of the vertical structures of the balcony and the ability of the balcony to capture solar radiation.

Temperature monitoring showed that over a year the air temperature of both glazed and unglazed balconies remained almost without an exception above the outdoor air temperature. On average, the temperatures of unglazed balconies were $2.0^{\circ} \mathrm{C}$ and those of glazed balconies $5.0^{\circ} \mathrm{C}$ higher than the outdoor air temperature. The three key factors affecting the glazed balcony temperatures seemed to be the level of air leakage in the balcony vertical structures, the balcony's ability to capture solar radiation, and the heat gain from an adjacent flat, in that order. The air tightness of the glazing was the most crucial factor, since it affected the results all the year round. Solar radiation was important from spring to autumn and heat gain in midwinter. [5] P. Saleh [6] made a study on few balconies in Lebanon and noticed that if we close the open edges with an extra layer of glass, the balconies turn into sunny or conservative spaces. Typically, in cold climates where there is a need to increase solar gains in the winter, these glazed balconies are commonly used as thermal buffer spaces; while in warm climates the open balconies are used as sub-spaces to shade the spaces.

To determine the temperature of the balcony requires a heat balance calculation, unheated space with multiple heat losses and intakes (from indoor space and from external solar radiation).[7]
From the balance equation, it results:

$$
Q_{o p, i}+Q_{v, i}+Q_{s}=Q_{o p, e}+Q_{v, e}
$$

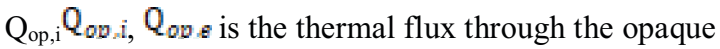
area from the interior, exterior side of the glazed space;

$\mathrm{Q}_{\mathrm{v}, \mathrm{i}}$ and $\mathrm{Q}_{\mathrm{v}, \mathrm{e}}$ are the thermal fluxes through the glazed areas from the balcony to indoor space and balcony to outdoor environment;

$\mathrm{Q}_{\mathrm{s}}$ is the thermal flux from solar gain.

Explaining the equation:

$$
\begin{aligned}
& \frac{A_{o p, i}}{R_{o p, i}}\left(\theta_{i}+\theta_{A}\right)+\frac{A_{v i}}{R_{v i}}\left(\theta_{i}+\theta_{A}\right)+Q_{A}=\frac{A_{o p, e}}{R_{o p, e}}\left(\theta_{A}-\theta_{e}\right)+ \\
& +\frac{A_{v e}}{R_{v e}}\left(\theta_{A}-\theta_{e}\right)+\operatorname{nV} \rho c\left(\theta_{A}-\theta_{e}\right)(2)
\end{aligned}
$$

where:

- $\mathrm{A}_{\mathrm{op}, \mathrm{i}}$ is the opaque area balcony to indoor space $\left[\mathrm{m}^{2}\right]$;

- $\mathrm{A}_{\mathrm{op}, \mathrm{e}}$ is the opaque area balcony to outdoor space $\left[\mathrm{m}^{2}\right]$;

- $\mathrm{A}_{\mathrm{v}, \mathrm{i}}$ is the glazed area balcony to indoor space $\left[\mathrm{m}^{2}\right]$

- $A_{v, e}$ is the glazed area balcony to outdoor space $\left[\mathrm{m}^{2}\right]$

- $\mathrm{R}_{\mathrm{op}, \mathrm{i}}$ is the thermal resistance of the opaque area balcony to indoor space $\left[\mathrm{m}^{2} \mathrm{~K} / \mathrm{W}\right]$

- $R_{o p, e}$ is the thermal resistance of the opaque area balcony to outdoor space $\left[\mathrm{m}^{2} \mathrm{~K} / \mathrm{W}\right]$

- $\mathrm{R}_{\mathrm{v}, \mathrm{i}}$ is the thermal resistance of the glazed area balcony to indoor space $\left[\mathrm{m}^{2} \mathrm{~K} / \mathrm{W}\right]$

- $\mathrm{R}_{\mathrm{v}, \mathrm{e}}$ is the thermal resistance of the glazed area balcony to outdoor space $\left[\mathrm{m}^{2} \mathrm{~K} / \mathrm{W}\right]$

- $\theta_{\mathrm{i}}, \theta_{\mathrm{e}}$ are the indoor space temperature and outdoor environment $\left[{ }^{\circ} \mathrm{C}\right]$;

- $\theta_{\mathrm{s}}$ is the balcony air temperature $\left[{ }^{\circ} \mathrm{C}\right]$;

$-\mathrm{V}$ is the balcony air volume $\left[\mathrm{m}^{3}\right]$

$-\mathrm{n}$ is the ventilation rate $\left[\mathrm{h}^{-1}\right]$

From the equation (2) results:

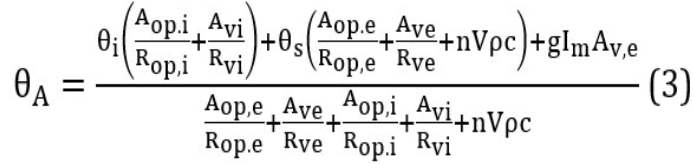

The equation (3) sets the relation between the adopted criterion, the air temperature from the greenhouse space and the other parameters.

As variable parameters, the following parameters were considered:

- the thermal resistance of walls that separate the greenhouse space from the heated space (related to its area);

- the thermal resistance of opaque area of the glazed space (related to its area);

- the orientation toward cardinal points. 


\subsection{Description of the studied balconies}

\subsubsection{Balcony \#1}

The experimental and numerical study was carried out using a classic balcony located in an apartment situated in a residential area in Bucharest, more exactly Pantelimon boulevard and has the following characteristics: $1^{\text {st }}$ floor, construction year: 1981, thermal rehabilitation: Yes (since 2012), glazed balcony: Yes ( $\mathrm{PVC}$ double glazed windows $\mathrm{R}=0.56 \mathrm{~m}^{2} \mathrm{~K} / \mathrm{W}$ ), heating system: heating boiler (24 $\mathrm{kW}$ Viessmann). The bedroom wall is entirely adjacent to the balcony while the living room has only a door to this space. It must be mentioned that the balcony has multiple heat losses: three outdoor walls (east, west and south), windows on the three orientations and an outdoor floor.
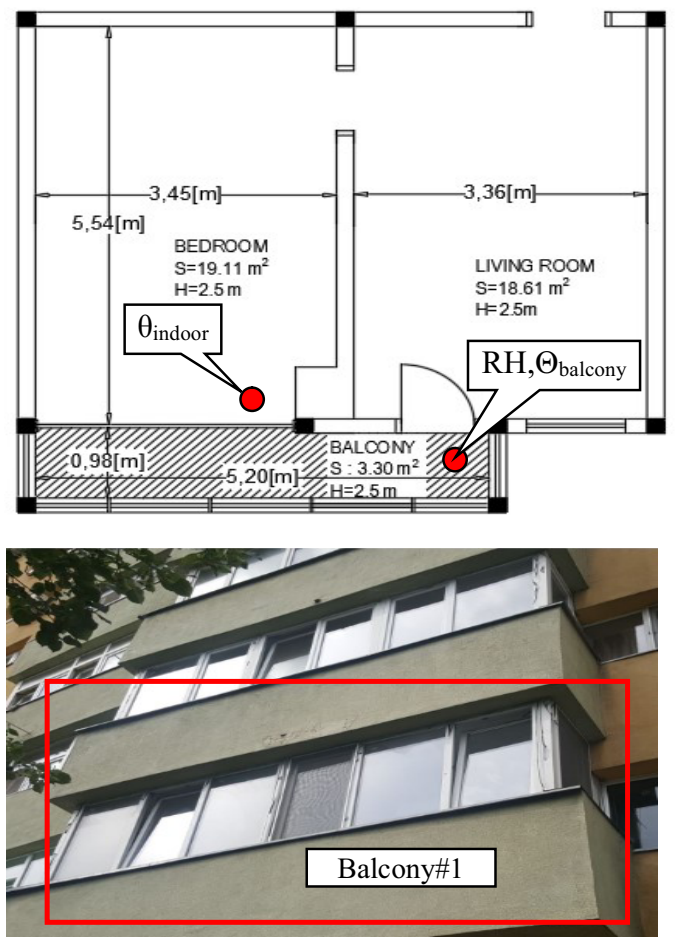

Fig. 1. Drawing of the balcony\#1 and outdoor photo

\subsubsection{Balcony \#2}

The experimental and numerical study was carried out using a classic balcony located in an apartment located in a residential area of Bucharest, more exactly on Postasului Street, and has the following characteristics: $3^{\text {rd }}$ floor, construction year: 1979, thermal rehabilitation: Yes (from 2016), double-glazed windows: Yes (PVC double-glazed windows $\mathrm{R}=0.56 \mathrm{~m}^{2} \mathrm{~K} / \mathrm{W}$ ), heating system from the city network. The wall of the living room is entirely adjacent to the balcony. This balcony has multiple heat losses: three outer walls (east, west and north), windows two orientations (west, north).
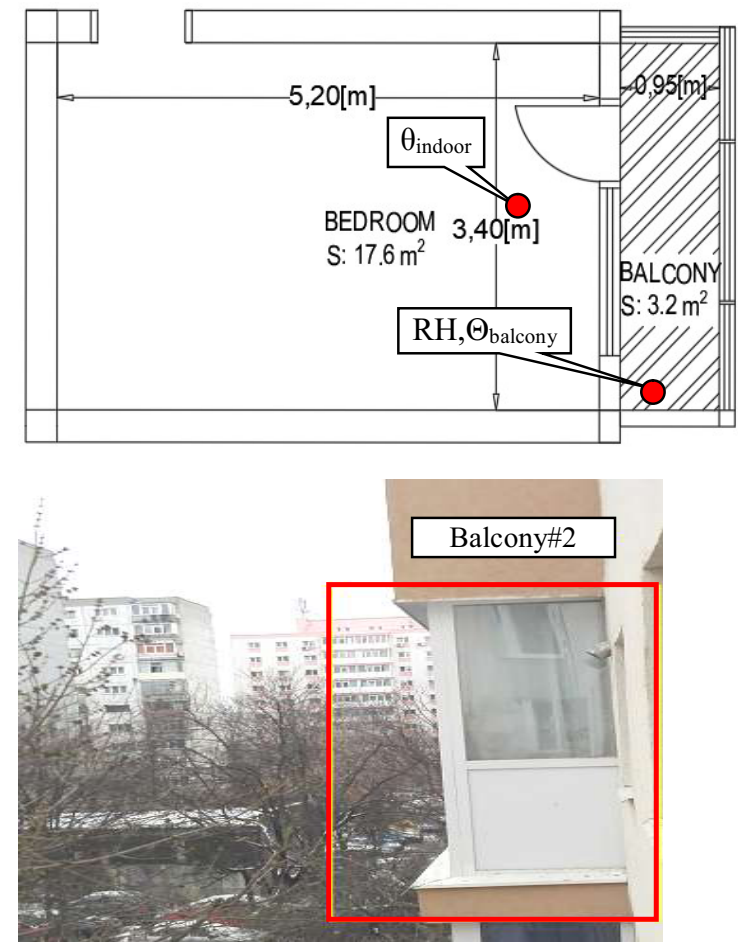

Fig. 2. Drawing of the balcony $\# 2$ and outdoor photo

\subsubsection{Balcony \#3}

The experimental and numerical study was carried out using a classic balcony of an apartment in sector 3 of the capital, more precisely on Baba Novac Street and has the following characteristics: 1st floor, construction year: 1961, thermal rehabilitation: Yes (since 2013), insulating windows: Yes (PVC double-glazed windows $\mathrm{R}=0.56$ $\mathrm{m}^{2} \mathrm{~K} / \mathrm{W}$ ), heating system from the city network. The kitchen wall is entirely adjacent to the balcony while the living room has only a door to this space. This balcony has heat loss through the outer wall from the north and through its windows.

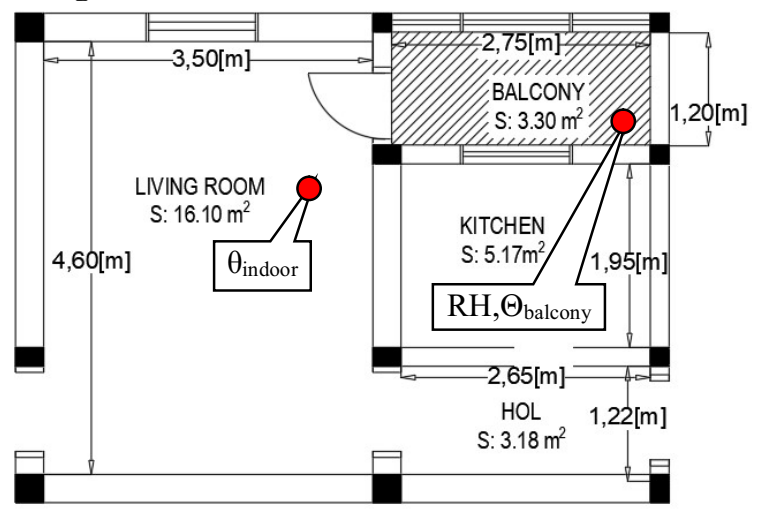




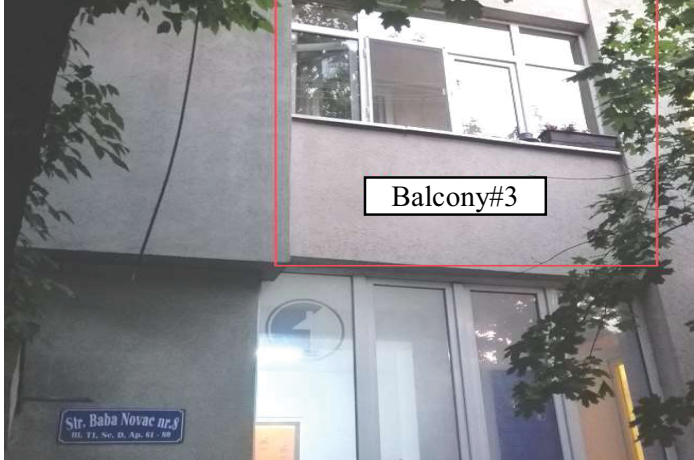

Fig. 3. Drawing of the balcony $\# 3$ and outdoor photo

\subsubsection{Summary}

Table 2. The characteristics of the studied blocks

\begin{tabular}{|l|c|c|c|}
\hline \multicolumn{1}{|c|}{ Characteristics } & B\#1 & B\#2 & B\#3 \\
\hline Construction year & 1981 & 1979 & 1961 \\
\hline Thermal rehabilitation & YES & YES & YES \\
\hline Window types indoor/balcony & PVC & PVC & PVC \\
\hline Balcony perimeter & 12.4 & 8.7 & 7.9 \\
\hline Balcony area & 3.3 & 3.2 & 3.3 \\
\hline Balcony orientation & SSW & SSW & SSE \\
\hline Area interior walls & 13 & 8.5 & 12.9 \\
\hline Area of the exterior balcony walls & 17.9 & 13.2 & 6.9 \\
\hline Glazed area & 16.5 & 10.2 & 8.2 \\
\hline \% glazed area to wall balcony & $60 \%$ & $49 \%$ & $60 \%$ \\
\hline$\%$ glazed area to indoor wall & $47 \%$ & $43 \%$ & $37 \%$ \\
\hline
\end{tabular}

From Table 2 it can be concluded that all three balconies analyzed are fully glazed. The balcony with the highest percentage of window glass is the balcony\#1 and number \#3 (about $60 \%$ ), which receive the highest amount of solar radiation and have the largest heat exchange through the window surface, while the other has a lower heat exchange due to the low percentage of glazing area (49\%). Balconies \#1 and \#2 have a large percentage (approx. 47\% and 43\%) of the glazed area to wall balcony, which results in a higher heat exchange between the indoor space and the balcony. The surface of the windows allows a good natural illumination of the rooms.

\section{Experimental campaign}

The experimental analysis was carried out in two different campaigns depended on the external temperature, solar radiation, external humidity, orientation and location of the balcony.[8]The first campaign was realized during winter period and the second campaign was realized during spring season.

It was measured the air temperature and relative humidity on the balcony and inside the adjacent room for every 5 minutes. At the end of each campaign, the data from the devices was downloaded on the computer using professional software. In both experimental campaigns, professional devices have been used that have recorded and stored many values about the temperature and humidity of the space where they were located. One the used equipment's was TESTO $174 \mathrm{H}$ and KT-20 sensor. The mini-recorder TESTO $174 \mathrm{H}$ features integrated sensors that deliver long-term stable results and measure ambient temperature and humidity with a storage capacity of up to 16,000 and a readable screen that displays both the ongoing measurement and any breach of limit values. Both sensors have a good precision with an accuracy of $\pm 0.5^{\circ} \mathrm{C}$ and a resolution of $0.1{ }^{\circ} \mathrm{C}$ and for the humidity $\pm 3 \% \mathrm{rH}$ and a resolution of $0.1 \% \mathrm{rH}$.

\section{Results}

For the first balcony the results are summarized below:

Table 3.1. Temperatures during the 2 studied periods

\begin{tabular}{|l|c|c|c|}
\hline \multicolumn{1}{|c|}{ Average values } & B\#1 & B\#2 & B\#3 \\
\hline Outdoor temperature - winter & -0.3 & -0.3 & -0.3 \\
\hline Outdoor temperature - spring & 20.9 & 20.9 & 20.9 \\
\hline Indoor temperature - winter & 22.5 & 22.1 & 26.8 \\
\hline Indoor temperature - spring & 24 & 24.1 & 26.5 \\
\hline Balcony temperature - winter & 13.5 & 12 & 17.4 \\
\hline Balcony temperature - spring & 25.3 & 24.7 & 22 \\
\hline
\end{tabular}

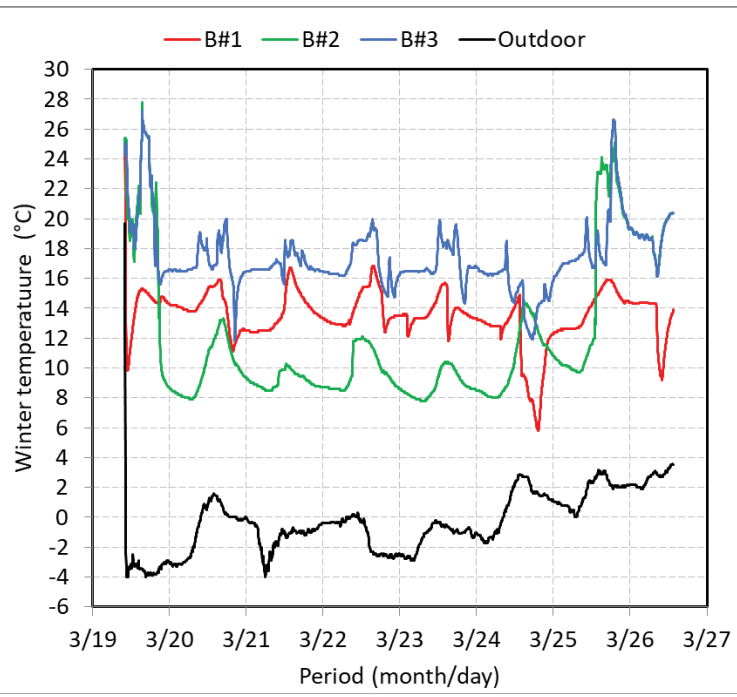

Fig.4. Temperature evolution during winter campaign

Balcony \#3 has the best warming part during the winter (Fig.4), with an average temperature of $17.4^{\circ} \mathrm{C}$. It has 3 interior walls, which lead to heated areas from which it receives a large amount of heat and a single exterior wall by which he loses the heat. 
Balcony \#1 is ranked second as the winter temperature, having a $13 \mathrm{~m}^{2}$ interior wall surface to receive warmth and a glass surface of $16.2 \mathrm{~m}^{2}$ that allows solar radiation to heat it. Its average winter temperature is $13.53^{\circ} \mathrm{C}$.

Balcony \#2 has the lowest average temperature during this cold $12.02^{\circ} \mathrm{C}$.

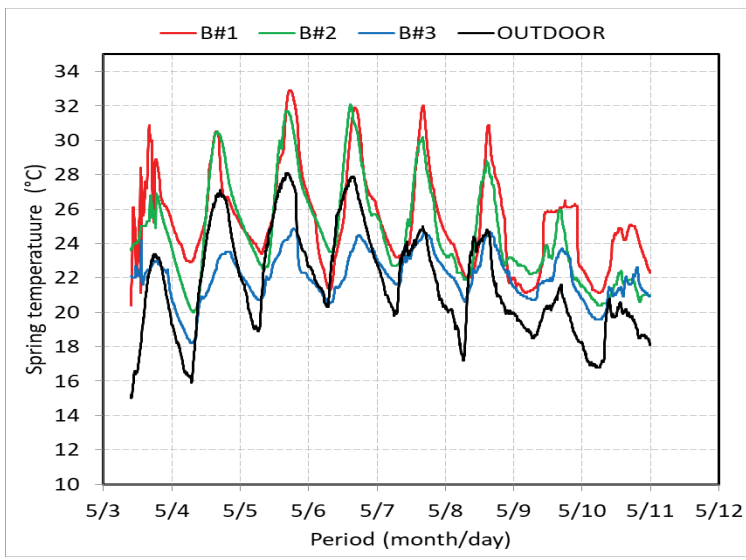

Fig.5. Temperature evolution during spring campaign

During spring time (Fig.5), balcony \#1 has the highest temperature, which is located on a higher floor, oriented on the SSW, allowing the solar radiation to pass through the glazed surface. Balcony \#3, located on the first floor, has the lowest temperature, sometimes less than the outside. This low temperature is due to the trees in front of the block that do not allow the sun to reach the balcony. Balcony \# 2 is like Balcony \# 1 , it is located on the same orientation, at a higher level, with a large glazed surface.

Table 3.2. Relative humidity in the 2 studied periods

\begin{tabular}{|l|c|c|c|}
\hline \multicolumn{1}{|c|}{ Average values } & B\#1 & B\#2 & B\#3 \\
\hline Outdoor humidity - winter & 82.5 & 82.5 & 82.5 \\
\hline Outdoor humidity - spring & 54.3 & 54.3 & 54.3 \\
\hline Balcony humidity - winter & 68 & 74 & 48.8 \\
\hline Balcony humidity - spring & 60.3 & 52.4 & 50.3 \\
\hline
\end{tabular}

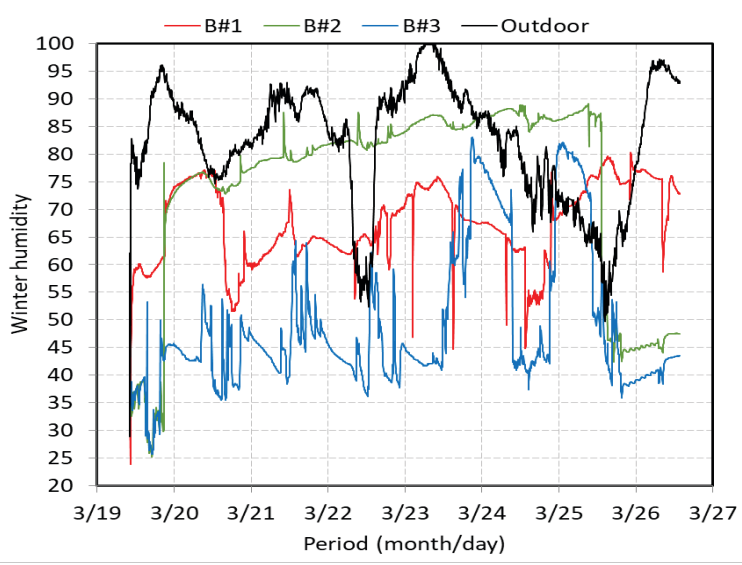

Fig.6. Relative humidity chart in winter period
High humidity of this period (Fig.6) is due to the weather conditions. The snow of this period significantly increases the humidity from the outside, influencing it also from the inside.

Other factors that influence indoor humidity, besides weather conditions, are drying the laundry and growing plants in the balcony.

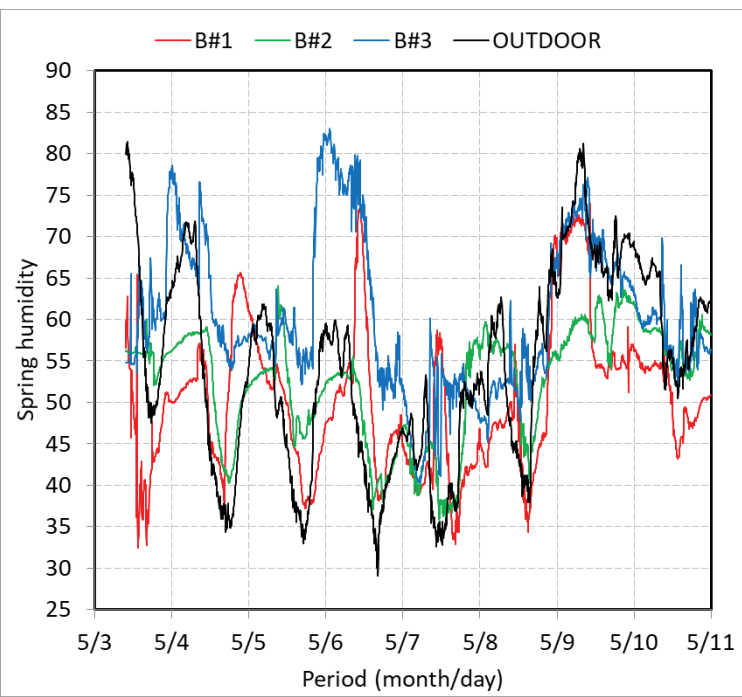

Fig.7. Relative humidity chart in spring period

Factors that have influenced an increase in the humidity are the weather conditions, the laundry drying and plant growth in the balconies.

\section{Simulation campaign}

To better illustrate the benefits/inconvenient from the energy demand point of view several simulations were realized. The software used for simulations is Trnsys 17 and balcony \#1 was chosen as study case.

Khaled Alhagla's goal was to reduce energy consumption by balancing beneficial natural light and solar heat. This work has used simulation techniques to identify the most effective windows with a good WWR.[9]

Large windows with good light exposure have a positive effect on the occupants' comfort and can save energy if the specifications of the windows. The authors analyzed the energy performance of different sized windows in a hospital room to find the most effective types of glass. The results show that adopting wider windows with the appropriate glazing can reduce the demand for heating and cooling energy.[10]

Two classes were studied, one eastbound and one westward, with the help of lighting and energy simulation programs: DIALux Evo 6.0, DesignBuilder 5.5 and EnergyPlus 8.9. The results of the simulations showed that a glass ratio of $50 \%$ would reduce the requirement for artificial lighting by at least $15 \%$.[11] 


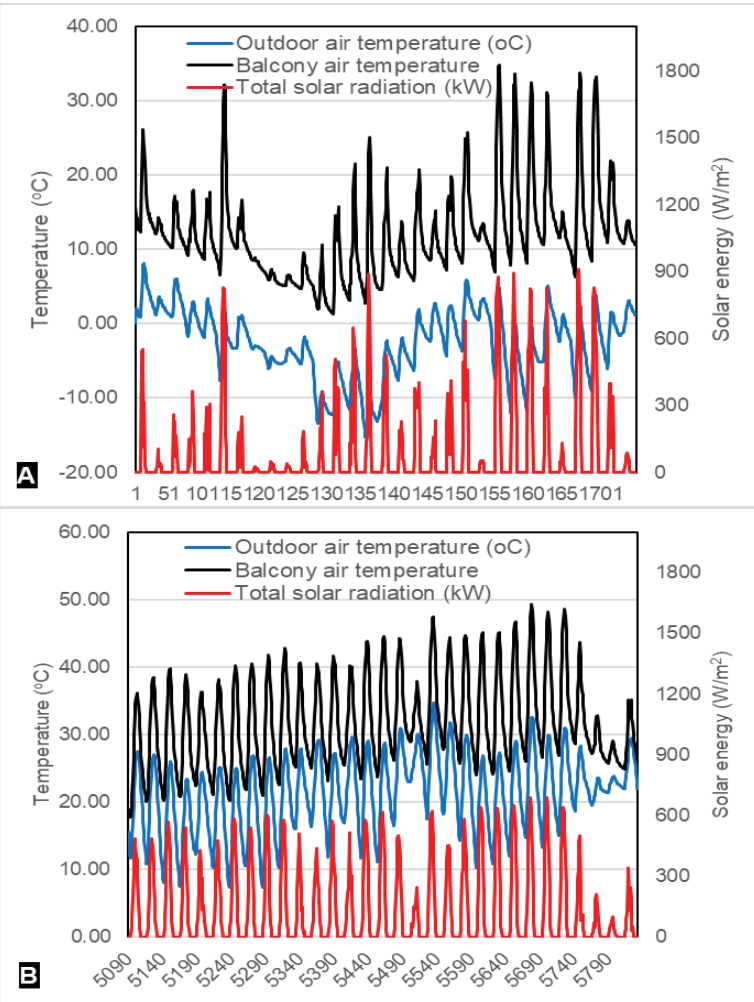

Fig.8. Balcony air temperature during A. winter season (January) and B. summer season (August)

The temperatures in the winter balcony are higher by about $15^{\circ} \mathrm{C}$ due to the solar radiation, which leads to energy saving. During the summer, the temperatures in the balcony greatly increase and can exceed $50^{\circ} \mathrm{C}$, there being the risk of overheating the balcony.
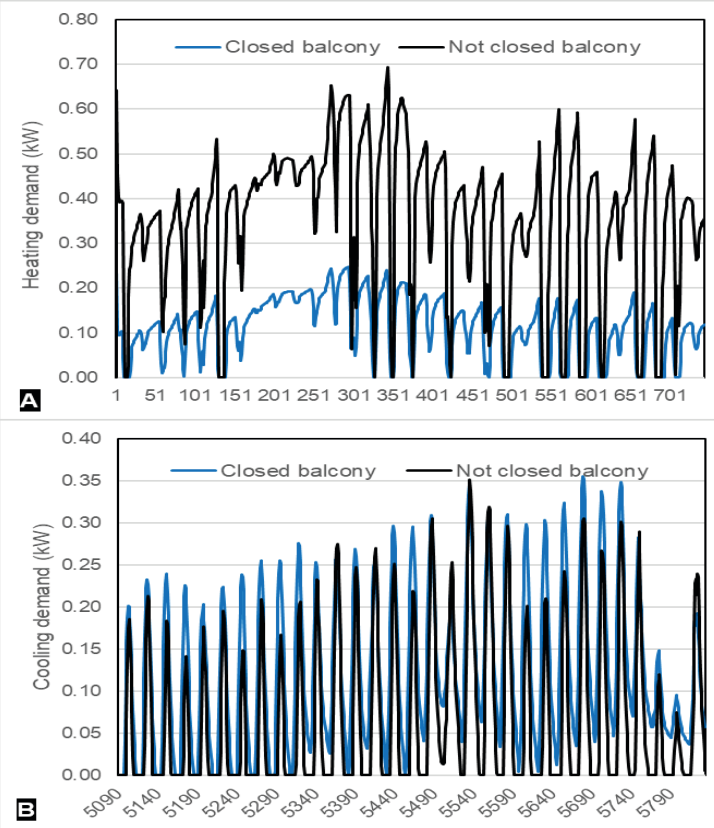

Fig.9. A. Heating demand (winter season - January) and B. Cooling demand (summer season - August)
The high temperature difference between the outside and the balcony plays a very important role in saving energy, so in winter, the heating costs are lower, for apartments with enclosed balconies.Summer costs are slightly higher for air conditioning due to overheating of the balconies.

\begin{tabular}{|l|c|c|c|c|c|c|}
\hline & \multicolumn{3}{|c|}{$\begin{array}{c}\text { Outdoor } \\
\text { temperature }\left({ }^{\mathbf{}} \mathbf{C}\right)\end{array}$} & \multicolumn{3}{c|}{$\begin{array}{c}\text { Balcony } \\
\text { temperature }\left({ }^{\mathbf{}} \mathbf{C}\right)\end{array}$} \\
\hline Month & Max & Min & Average & Max & Min & Average \\
\hline January & 8.15 & -15.30 & -2.56 & 34.77 & 1.34 & 12.03 \\
\hline August & 34.65 & 7.30 & 21.31 & 49.29 & 17.81 & 31.72 \\
\hline
\end{tabular}

The results of the simulations correspond to the data recorded by the temperature sensors we had placed in the 3 studied balconies.

\begin{tabular}{|c|c|c|c|c|}
\hline $\begin{array}{c}\text { Bedroom } \\
\text { energy analysis }\end{array}$ & $\begin{array}{c}\text { Closed } \\
\text { balcony }\end{array}$ & $\begin{array}{c}\text { Not closed } \\
\text { balcony }\end{array}$ & $\begin{array}{c}\text { Difference } \\
(\mathrm{kWh})\end{array}$ & $\begin{array}{c}\text { Difference } \\
(\%)\end{array}$ \\
\hline $\begin{array}{c}\text { Heating demand } \\
(\mathrm{kWh})\end{array}$ & 299.90 & 1291.75 & -991.86 & $-77 \%$ \\
\hline $\begin{array}{c}\text { Cooling demand } \\
(\mathrm{kWh})\end{array}$ & 442.99 & 286.69 & 156.30 & $55 \%$ \\
\hline $\begin{array}{c}\text { Total energy } \\
\text { demand }(\mathrm{kWh})\end{array}$ & 742.89 & 1578.45 & -835.56 & $-53 \%$ \\
\hline
\end{tabular}

In the table above we have heating and cooling consumption for a closed balcony and an open balcony. It can be noticed that for heating a closed balcony during the winter, the amount of energy is much smaller than for an open one, the difference between the 2 types are about $990 \mathrm{kWh}$.

In summer, cooling consumption is slightly higher at a closed balcony than an open one, but overall, saving energy in the winter makes closed balconies a much better choice than open ones.

\section{Conclusions}

After measurements of ambient temperature and humidity in space, during the second experimental campaign, we concluded that a closed and thermally rehabilitated balcony showed a winter advantage because the outdoor wind losses are small and the indoor temperature difference balcony and outdoor temperature of the balconies in the experimental study ranged between 13 and $17^{\circ} \mathrm{C}$, and in the period of time the temperature in these balconies is raised and there is a risk of overheating.

The results of the \# 1 balloon simulations made with the Trnsys 17 software show a good energy saving in the cold period, but a higher cooling demand in warm weather. The simulation also showed us the close connection between the temperature in the balcony and the solar radiation that grow and decrease simultaneously.

At the end of the two campaigns, we came to the conclusion that a closed and thermally rehabilitated balcony is the best solution, being proven to have a great winter advantage but a small summer disadvantage.

Too much moisture in the indoor air can lead to the appearance of dampness, mold or other bacteriological environments. These can also cause a variety of health 
problems, from allergic reactions to asthma attacks and pneumonia.

\section{References}

1. Budescu M., Țăranu N., Ciongradi I., IsopescuD., GavrilașI., Ciupală A. M.,Lungu I., Oprișan G. Building Rehabilitation, Ed. Academică Matei-Teiu Botez, Iaşi 2003;

2. Cezary Misiopecki, Marine Bouquin, Arild Gustavsen, Bjørn Petter Jelle, Thermal modeling and investigation of the most energy-efficient window position, Energy and Buildings 158(2018) 1079-1086;

3. Tim Ariosto Ali, M.Memari Ryan, L.Solnosky, Development of designer aids for energy efficient residential window retrofit solutions, Sustainable Energy Technologies and Assessments 33(2019) 113

4. W.J.Hee, M.A.Alghoul ,B.Bakhtyar, OmKalthum Elayeb ,M. A.Shameri, M.S.Alrubaih, K.Sopian, The role of window glazing on daylighting and energy saving in buildings, Renewable and Sustainable Energy Reviews 42(2015) 323-343

5. Kimmo Hilliaho, Arto Köliö, Toni Pakkala, Jukka Lahdensivu, Juha Vinha, Effects of added glazing on Balcony indoor temperatures: Field measurements ,Energy and Buildings 128 (2016) 458-472.

6. Philip H. Saleh, Thermal performance of glazed balconies within heavyweight/thermal mass buildings in Beirut, Lebanon's hot climate, Energy and Buildings 108 (2015) 291-303.

7. Irina Bliuc, Irina Baran, The Quality of the Inside Environment and the Energy Efficiency of Buildings,Physics of Constructions;

8. K. Hilliaho,V. Kovalainen,S.Huuhka, J.Lahdensivu, Glazed spaces: A simplified calculation method for the evaluation of energy savings and interior temperatures , Energy and Buildings 125 (2016) 2744;

9. Khaled Alhagla ,Alaa Mansour ,Rana Elbassuoni, Optimizing windows for enhancing daylighting performance and energy saving, Alexandria Engineering Journal,58(2019) 283-290;

10. Silvia Cesaria ,Paolo Valdiserri ,Maddalena Coccagna,Sante Mazzacane, Energy savings in hospital patient rooms: the role of windows size and glazing properties,Energy Procedia 148 (2018) 1151-1158;

11. Touraj Ashrafian,NazaninMoazzen, The impact of glazing ratio and window configuration on occupants' comfort and energy demand: The case study of a school building in Eskisehir, Turkey, Sustainable Cities and Society 47 (2019) 101483; 